\title{
Design of Linear Controllers applied to an ethanol steam reformer for PEM fuel cell applications
}

\author{
V. García ${ }^{1}$, M. Serra ${ }^{1}$, J. Llorca $^{2}$, J. Riera $^{1}$ \\ 1 Institut de Robòtica i Informàtica Industrial (CSIC-UPC), Llorens i Artigas 4-6 08028, Barcelona, Spain; \\ 2 Institut de Tècniques Energètiques (UPC), Diagonal 647 ed. ETSEIB 08028, Barcelona, Spain.
}

vgarcia@iri.upc.edu

\begin{abstract}
This paper focuses on the design of a controller for a low temperature ethanol steam reformer for the production of hydrogen to feed a Protonic Exchange Membrane (PEM) fuel cell. It describes different control structures for the reformer and treats the control structure selection of this Multiple Input Multiple Output (MIMO) system. For each control structure, decentralised $2 \times 2$ controllers are implemented and a Proportional Integral (PI) control action is implemented in each control loop. The PI parameters are tuned and the performance of the different linear controllers is compared though simulation. For the evaluation of the proposed controllers, the response time for different initial conditions and changes in the references is analysed, as well as the behaviour of the controlled system in front of disturbances.
\end{abstract}

Keywords: Hydrogen generation, Ethanol steam reforming, Low temperature reforming, MIMO systems, Linear control

\section{Introduction}

Bio-ethanol is considered a $\mathrm{CO}_{2}$-neutral fuel, suited to diminish the use of the conventional fossil fuels based on petroleum and natural gas. In previous contributions [1-2] the authors reported results addressing the dynamic modelling and controllability analysis of a low temperature catalytic ethanol steam reformer for fuel cell hydrogen feeding. In this work, the design of linear controllers suitable for this ethanol reformer is reported and a comparative analysis between different controllers is performed through simulation. Up until now there have only been a few works that address the design and implementation of controllers for fuel reformers [3,4], and none of these have used ethanol fuel. The control objectives considered are to keep hydrogen and CO flowrates at their reference values, oscillating around the nominal conditions. This nominal operating point maximises hydrogen yield and minimizes CO production, which is necessary to prevent CO poisoning of PEM fuel cells. Our ethanol reformer operates in three separate stages: ethanol dehydrogenation to acetaldehyde and hydrogen, acetaldehyde steam reforming and water gas shift reaction. The authors already modelled the reformer by using a one-dimensional, pseudo-homogeneous model based on mass and energy balances [1]. Based on the controllability analysis made in [2], only five control structures are considered in this work in the search of the best controllers.

\section{Control Structures}

The reformer is a MIMO system that has multiple inputs (possible manipulated variables) and multiple outputs (variables of interest). As explained in [2] the flowrates of ethanol and water at the reactor entrance $\left(\mathrm{F}_{\mathrm{C} 2 \mathrm{H} 5 \mathrm{OH}}\right.$, $\left.\mathrm{F}_{\mathrm{H} 2 \mathrm{O}}\right)$, the temperature of the entering mixture $\left(\mathrm{T}_{\mathrm{gas}, \mathrm{e}}\right)$, and the temperatures of the furnaces of the three reforming stages $\left(\mathrm{T}_{\mathrm{F}, \mathrm{S} 1}, \mathrm{~T}_{\mathrm{F}, \mathrm{S} 2}, \mathrm{~T}_{\mathrm{F}, \mathrm{S} 3}\right)$ have been considered as inputs. As outputs to be controlled we have considered the flowrates of $\mathrm{H}_{2}$ and $\mathrm{CO}\left(\mathrm{F}_{\mathrm{H} 2}\right.$ and $\left.\mathrm{F}_{\mathrm{CO}}\right)$ at the output of the reformer.

A controllability analysis based on a linear model was done in [2]. According to RGA, MRI and CN controllability indexes, five different control structures were selected as the most promising ones for the control of $\mathrm{F}_{\mathrm{H} 2}$ and $\mathrm{F}_{\mathrm{CO}}$. These structures are defined in Table 1 and Figure 1. The five control structures consist of a decentralised control. The control variables $\left(U_{1}\right.$ and $U_{2}$ in Figure 1) depend on the chosen control variables in each case; for example, Structure 1 corresponds to the manipulation of $\mathrm{F}_{\mathrm{C} 2 \mathrm{H} 5 \mathrm{OH}}$ for the control of $\mathrm{F}_{\mathrm{H} 2}$, and the manipulation of $\mathrm{F}_{\mathrm{H} 2 \mathrm{O}}$ for the control of $\mathrm{F}_{\mathrm{CO}}$.

For all the structures, the controllers that have been used in each one of the control loops are PI controllers. 
Table 1. Control structures

\begin{tabular}{l|ll} 
& Loop 1 & Loop 2 \\
& & \\
\hline Structure 1 & $\mathrm{F}_{\mathrm{C} 2 \mathrm{H} 5 \mathrm{OH}} \rightarrow \mathrm{F}_{\mathrm{H} 2}$ & $\mathrm{~F}_{\mathrm{H} 2 \mathrm{O}} \rightarrow \mathrm{F}_{\mathrm{CO}}$ \\
Structure 2 & $\mathrm{F}_{\mathrm{C} 2 \mathrm{H} 5 \mathrm{OH} \rightarrow \mathrm{F}_{\mathrm{H} 2}}$ & $\mathrm{~F}_{\mathrm{F}, \mathrm{S} 2} \rightarrow \mathrm{F}_{\mathrm{CO}}$ \\
Structure 3 & $\mathrm{F}_{\mathrm{H} 2 \mathrm{O}} \rightarrow \mathrm{F}_{\mathrm{H} 2}$ & $\mathrm{~F}_{\mathrm{F}, \mathrm{S} 2 \rightarrow \mathrm{F}_{\mathrm{CO}}}$ \\
Structure 4 & $\mathrm{F}_{\mathrm{gas}, \mathrm{e}} \rightarrow \mathrm{F}_{\mathrm{H} 2}$ & $\mathrm{~F}_{\mathrm{F}, \mathrm{S} 2 \rightarrow \mathrm{F}_{\mathrm{CO}}}$ \\
Structure 5 & $\mathrm{F}_{\mathrm{F}, \mathrm{S} 1 \rightarrow \mathrm{F}_{\mathrm{H} 2}}$ & $\mathrm{~F}_{\mathrm{FS} 2} \rightarrow \mathrm{F}_{\mathrm{CO}}$
\end{tabular}

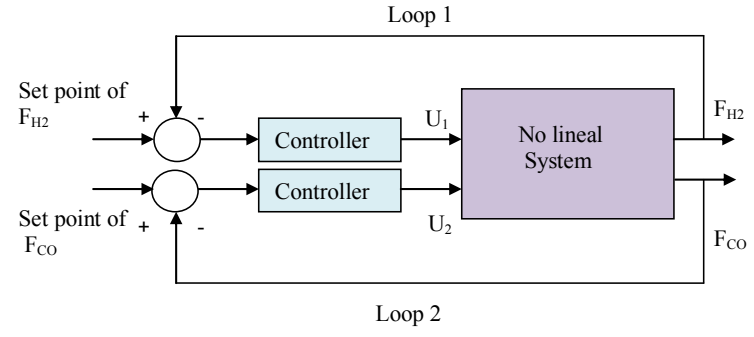

Figure 1- Basic control structure.

In order to obtain a versatile system able to adapt its production to the changing operating conditions of a fuel cell the controller must control the flow of the final products, $\mathrm{F}_{\mathrm{CO}}$ and $\mathrm{F}_{\mathrm{H} 2}$, to a reference value. The reference tracking is therefore the main objective of the controller. Anyway, the analysis of the controlled system is based on reference changes and disturbance rejection. For this reason we have studied the behaviour of the controllers introducing changes in the non-manipulated input variables to evaluate if the controller is robust against these disturbances. In some cases, the control system is evaluated at different operating points. The nominal operating conditions are defined in Table 2 and in Table 3 we defined the outputs nominal's values.

Table 2. Nominal operating conditions

\begin{tabular}{c|cccccc} 
& $\begin{array}{c}\mathrm{F}_{\mathrm{C} 2 \mathrm{H} 5 \mathrm{OH}, \mathrm{e}} \\
10^{-3} \\
{[\mathrm{~mol} / \mathrm{s}]}\end{array}$ & $\begin{array}{c}\mathrm{F}_{\mathrm{H} 2 \mathrm{O}, \mathrm{e}} \\
10^{-3} \\
{[\mathrm{~mol} / \mathrm{s}]}\end{array}$ & $\begin{array}{c}\mathrm{T}_{\text {gas,e }} \\
{[\mathrm{K}]}\end{array}$ & $\begin{array}{c}\mathrm{T}_{\mathrm{F}, \mathrm{S} 1} \\
{[\mathrm{~K}]}\end{array}$ & $\begin{array}{c}\mathrm{T}_{\mathrm{F}, \mathrm{S} 2} \\
{[\mathrm{~K}]}\end{array}$ & $\begin{array}{c}\mathrm{T}_{\mathrm{F}, \mathrm{S} 3} \\
{[\mathrm{~K}]}\end{array}$ \\
\hline $\mathrm{OP}_{\mathrm{n}}$ & 1.34 & 8.21 & 648 & 648 & 678 & 613
\end{tabular}

Table 3. Outputs nominal values

\begin{tabular}{c|cccccc} 
& $\begin{array}{c}\mathrm{F}_{\mathrm{H} 2, \text { out }} \\
10^{-3} \\
{[\mathrm{~mol} / \mathrm{s}]}\end{array}$ & $\begin{array}{c}\mathrm{F}_{\mathrm{CO}, \text { out }} \\
10^{-3} \\
{[\mathrm{~mol} / \mathrm{s}]}\end{array}$ & $\begin{array}{c}\eta^{\mathrm{H} 2} \\
{[\%]}\end{array}$ & $\begin{array}{c}\mathrm{x}_{\mathrm{C} 2 \mathrm{H} 5 \mathrm{OH}} \\
{[\%]}\end{array}$ & $\begin{array}{c}\mathrm{x}_{\mathrm{C} 2 \mathrm{H} 4 \mathrm{O}} \\
{[\%]}\end{array}$ & $\begin{array}{c}\mathrm{y}_{\mathrm{CO}} \\
{[\%]}\end{array}$ \\
\hline $\mathrm{OP}_{\mathrm{n}}$ & 6.39 & 1.34 & 79.65 & 93.41 & 84.51 & 0.83
\end{tabular}

\section{Control specifications}

There are several considerations to take into account in assessing a controller's response to a change of reference or disturbance. In this work we have considered mainly the following:

- The controlled variable should reach its desired value as quickly as possible.

- The controlled variable should not be too oscillatory or have strong peaks.

- The manipulated variable should not be subject to major changes, as they can affect other parts of the process.

\section{Simulation results}

In this section the response of the system controlled by the different control structures is shown. Simulations are done with the non-linear model described in [1]. In Table 4, the tuning parameters selected for each structure are shown. Two tuning methods have been adopted: Zigler-Nichols (Z-N) and Trial and Error (T-E). The trial and error method has been used when the Z-N tuning parameters show important limitations in terms of control and stability. Since we are dealing with PI controllers, to tune the controllers parameters properly by trial and error through simulation is a possible task. 
Table 4. PI parameters obtained by the Z-N and T-E methods

\begin{tabular}{l|llllr} 
& Methods & \multicolumn{2}{c}{ Loop 1 } & \multicolumn{2}{c}{ Loop 2 } \\
& & $\mathrm{Kp}$ & $\mathrm{Ki}$ & $\mathrm{Kp}$ & $\mathrm{Ki}$ \\
\hline Structure 1 & T-E & $4 \times 10^{-2}$ & $7.3 \times 10^{-3}$ & $-9 \times 10^{-1}$ & $-6 \times 10^{-1}$ \\
Structure 2 & Z-N & 0.1 & $4.3 \times 10^{-3}$ & $3.1 \times 10^{5}$ & $1.0 \times 10^{4}$ \\
Structure 3 & T-E & 0.6 & $2.1 \times 10^{-2}$ & $2.8 \times 10^{6}$ & $9.3 \times 10^{4}$ \\
Structure 4 & T-E & $9.9 \times 10^{2}$ & $2.1 \times 10^{3}$ & $2.8 \times 10^{3}$ & $5 \times 10^{3}$ \\
Structure 5 & Z-N & $7.2 \times 10^{4}$ & $6.0 \times 10^{2}$ & $6.5 \times 10^{5}$ & $5.4 \times 10^{5}$
\end{tabular}

\section{Structure 1}

In Figure 2 we can see the controlled outputs $\left(\mathrm{F}_{\mathrm{H} 2}\right.$ and $\left.\mathrm{F}_{\mathrm{CO}}\right)$ for the following reference tracking problem: $10 \%$ increase in the $\mathrm{CO}$ reference and $10 \%$ increase in the $\mathrm{H}_{2}$ reference at $\mathrm{t}=50 \mathrm{~s}$ and $\mathrm{t}=400 \mathrm{~s}$, respectively. The initial operating point is set at the nominal operating conditions. Both controlled variables are brought at their reference values without important peaks and oscillations in approximately 200s; the response time cannot be reduced significantly changing the controller parameters.

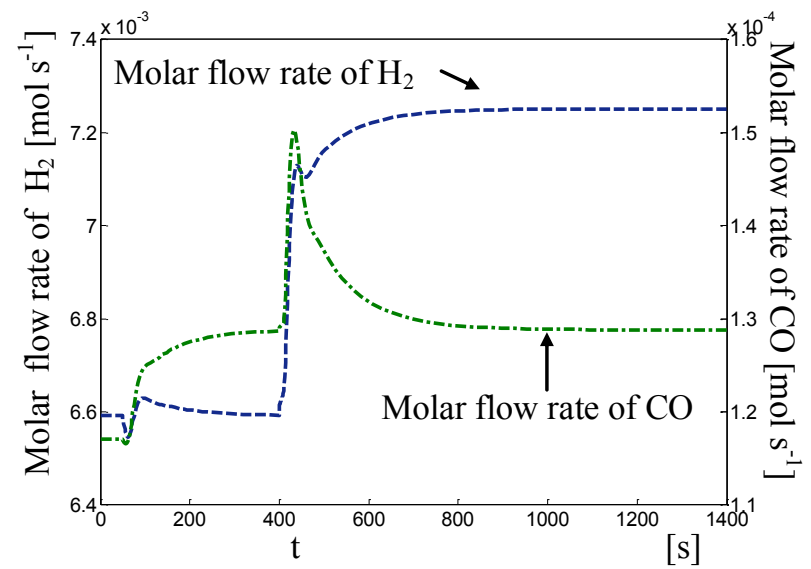

Figure 2- $\mathrm{F}_{\mathrm{H} 2}$ and $\mathrm{F}_{\mathrm{CO}}$ curves for $10 \%$ set point changes at $\mathrm{t}=50$ and $\mathrm{t}=400 \mathrm{~s}$

In Figure 3, the outputs of the controller can be seen. We can see that $17 \%$ increase in the flowrate of ethanol is necessary to produce a $10 \%$ increase in the controlled output $\left(\mathrm{F}_{\mathrm{H} 2}\right)$. In addition a $6 \%$ decrease in the flowrate of water is necessary to produce a $10 \%$ increase in the controlled output $\left(\mathrm{F}_{\mathrm{CO}}\right)$. With these values we can consider that the control effort under these conditions is reasonable in both loops, although from the results we can conclude that the first loop is the one that requires a larger effort to control the system.

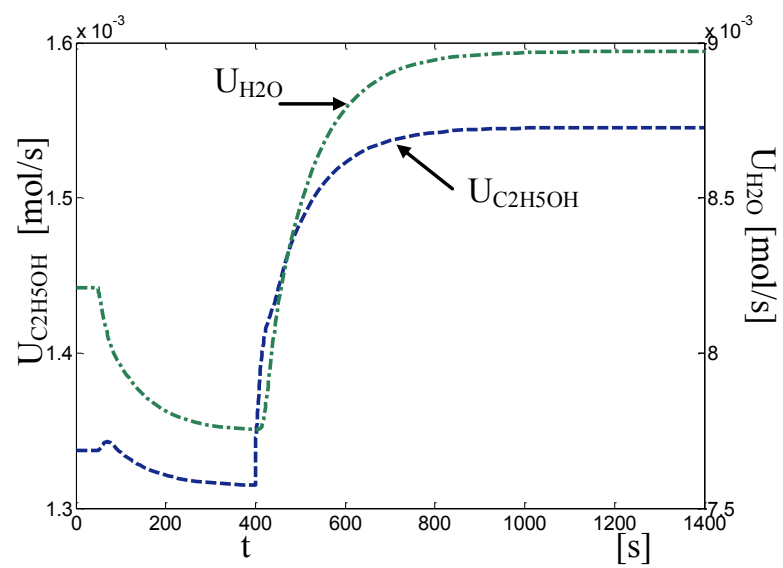

Figure 3- Controller outputs for $10 \%$ set point changes at $\mathrm{t}=50$ and $\mathrm{t}=400 \mathrm{~s}$. 


\section{Structure 2}

As indicated in Table 4, in this structure the parameters of the controller have been tuned with the T-E (trial and error) method. In Figure 4, the controlled variables are plot for the following simulation scenario: 1\% increase in the $\mathrm{CO}$ reference and $1 \%$ increase in the $\mathrm{H}_{2}$ reference at $\mathrm{t}=50 \mathrm{~s}$ and $\mathrm{t}=3600 \mathrm{~s}$, respectively. The reference tracking is achieved with proper profiles in about 2000 seconds.

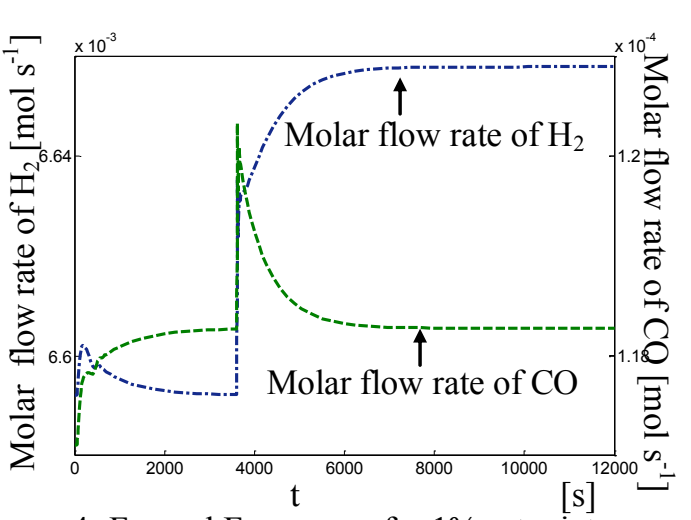

Figure $4-\mathrm{F}_{\mathrm{H} 2}$ and $\mathrm{F}_{\mathrm{CO}}$ curves for $1 \%$ setpoint changes at $\mathrm{t}=50$ and $\mathrm{t}=3600 \mathrm{~s}$.

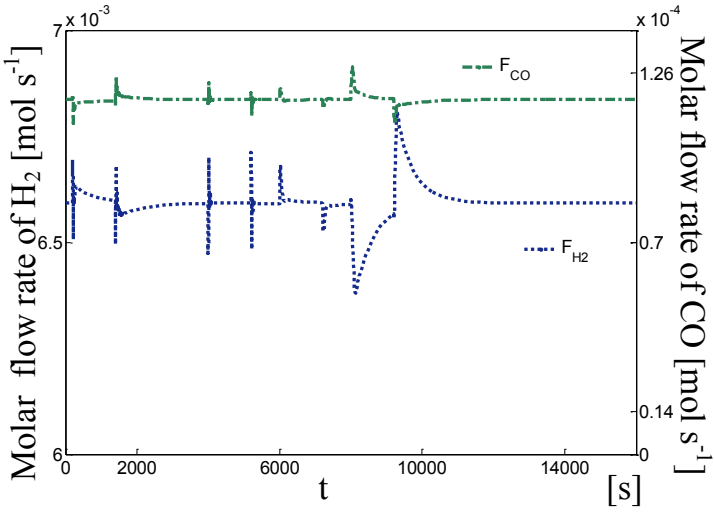

Figure 5- Molar flows of $\mathrm{H}_{2}$ and $\mathrm{CO}$ under changes in the non-manipualted inputs.

In Figure 5, $\mathrm{H}_{2}$ and $\mathrm{CO}$ molar flowrates, are represented again. The input variables $\mathrm{F}_{\mathrm{H} 2 \mathrm{O}}, \mathrm{T}_{\mathrm{gas}, \mathrm{e}}, \mathrm{T}_{\mathrm{F}, \mathrm{S} 1}$ and $\mathrm{T}_{\mathrm{F}, \mathrm{S} 3}$ are changed with steps of $2 \%$ at different times. In the figure we can see that the influence of $\mathrm{T}_{\mathrm{F}, \mathrm{S} 3}$ is much larger than the influence of the other perturbations but for all distrubances the control system is able to reject their effect. It can also be seen that $\mathrm{T}_{\mathrm{F}, \mathrm{S} 3}$ has a larger effect on $\mathrm{H}_{2}$ flowrate than on $\mathrm{CO}$ flowrate.

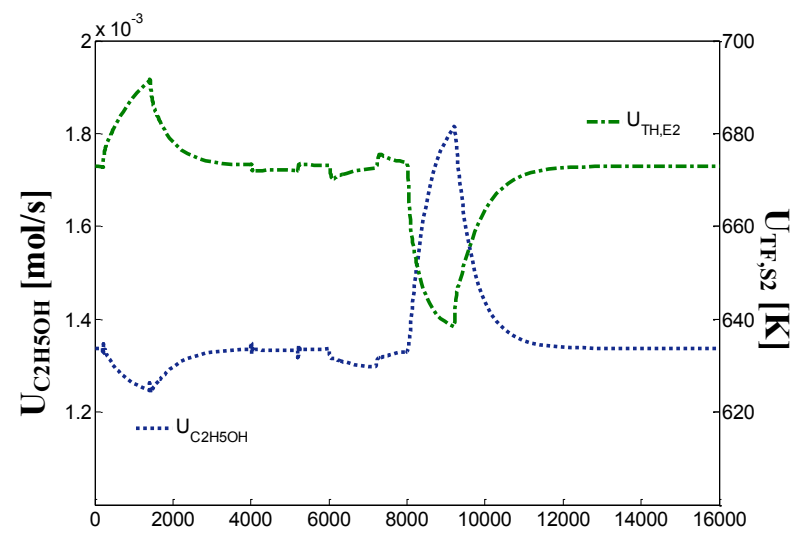

Figure 6- Controller outputs under step changes of 2\% in the non-manipulated inputs.

Figure 6 represents the outputs of the controller $\left(\mathrm{U}_{\mathrm{C} 2 \mathrm{H} 5 \mathrm{OH}}\right.$ and $\left.\mathrm{U}_{\mathrm{TF}, \mathrm{S} 2}\right)$ under the same operating conditions represented in figure 5 . Also we can see that the temperature of the $\mathrm{T}_{\mathrm{F}, \mathrm{S} 3}$ is the more influent input variable.

\section{Structures 3}

Figure 7 shows the molar flowrates of $\mathrm{H}_{2}$ and $\mathrm{CO}$ under the following conditions: $10 \%$ increase in the $\mathrm{CO}$ reference and $5 \%$ in the reference of $\mathrm{H}_{2}$ at $=50 \mathrm{~s}$ and $\mathrm{t}=400 \mathrm{~s}$, respectively. The outputs present an acceptable performance however, when the reference of CO changes, the output has a greater overshoot. This may seem logical because the increase is the double than that in the other reference value. The response time is approximatedly double than the response time with Structure 1. 

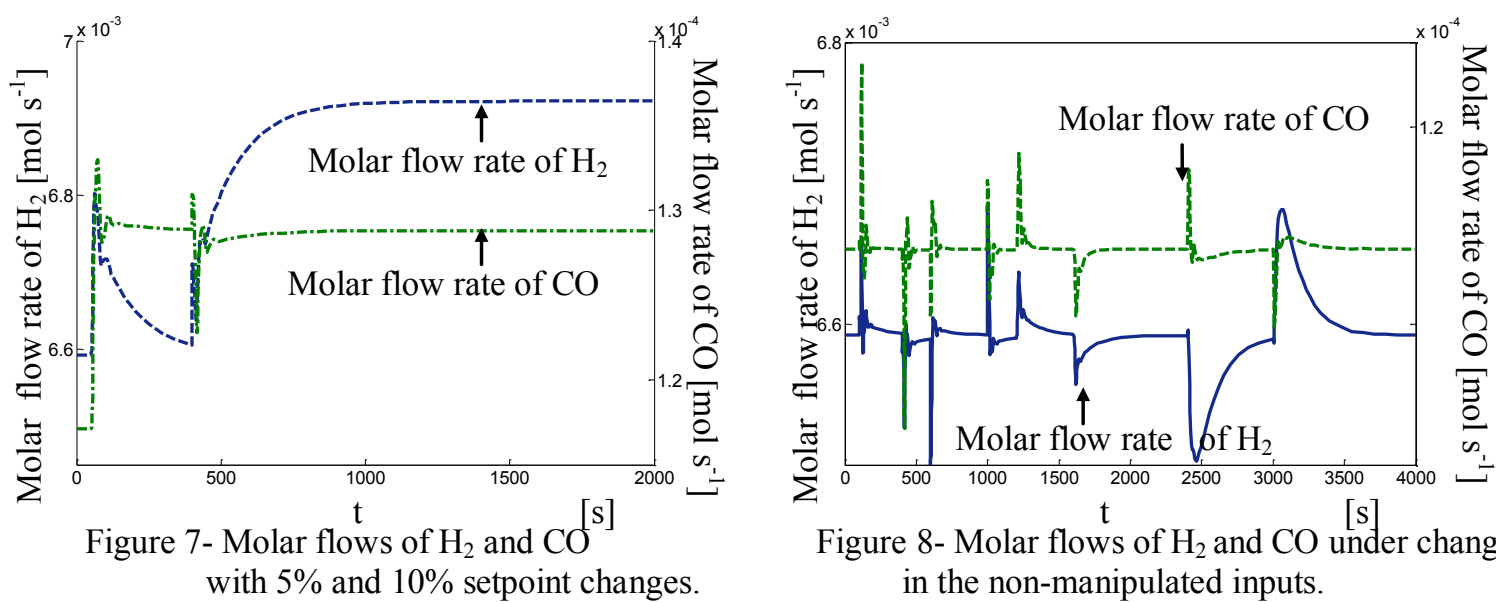

Figure 8- Molar flows of $\mathrm{H}_{2}$ and $\mathrm{CO}$ under changes in the non-manipulated inputs.

In Figure 8 we can see the $\mathrm{H}_{2}$ and $\mathrm{CO}$ molar flows under disturbances in the following input variables: $\mathrm{F}_{\mathrm{C} 2 \mathrm{H} 5 \mathrm{OH}}$, $\mathrm{T}_{\text {gas,e }}, \mathrm{T}_{\mathrm{F}, \mathrm{S} 1}, \mathrm{~T}_{\mathrm{F}, \mathrm{S} 3}$. The disturbances are implemented by steps of $2 \%$ at different times. In this case the influence of $\mathrm{T}_{\mathrm{F}, \mathrm{S} 2}$ is similar than the influence of $\mathrm{T}_{\mathrm{F}, \mathrm{S} 3}$. We can consider that the performance of the controller under the disturbances in the non-manipulated inputs is adecuate. As we saw in structure $2, \mathrm{~T}_{\mathrm{F}, \mathrm{S} 3}$ has a larger effect on $\mathrm{H}_{2}$ flowrate than on $\mathrm{CO}$ flowrate.

Figure 9 shows the outputs of the controller $\left(\mathrm{U}_{\mathrm{H} 2 \mathrm{O}}\right.$ and $\left.\mathrm{U}_{\mathrm{TF}, \mathrm{S} 2}\right)$ under the same operating conditions as in figure 7. The controller must produce a $0.4 \%$ increase in the flow of water to produce a $5 \%$ increase in the controlled output $\left(\mathrm{F}_{\mathrm{H} 2}\right)$, we can make an increase of $9.4 \%$ in the $\mathrm{U}_{\mathrm{TF}}$, 2 to produce an increase of $10 \%$ in the molar flow rate of $\mathrm{CO}$.

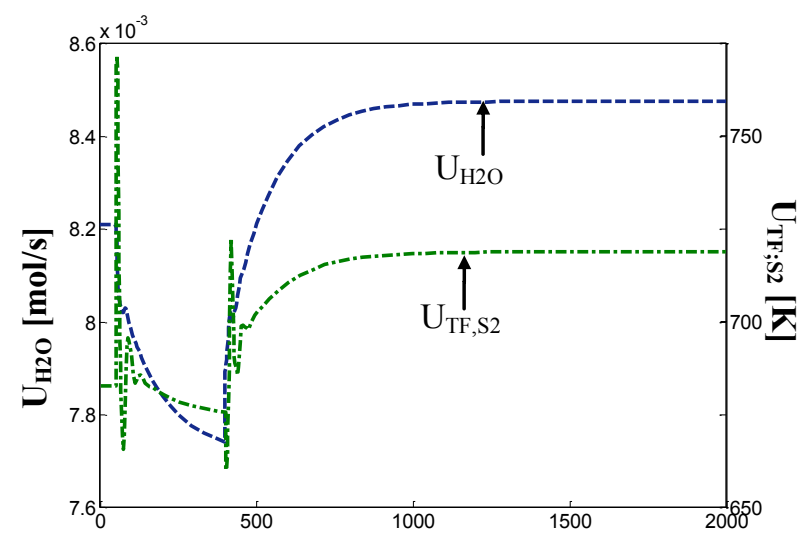

Figure 9- Controller outputs for $5 \%$ and $10 \%$ set point changes at $\mathrm{t}=50$ and $\mathrm{t}=400 \mathrm{~s}$.

\section{Structure 4}

In Figure 10 we represent the molar flows of $\mathrm{H}_{2}$ and $\mathrm{CO}$ for the Structure 4 facing $1 \%$ increase in the $\mathrm{CO}$ reference and $1 \%$ in the reference of $\mathrm{H}_{2}$ at $=400 \mathrm{~s}$ and $\mathrm{t}=15000 \mathrm{~s}$, respectively. This structure was the worst of those considered because the controlled response took too much time to reach its desired value, even with setpoint changes of only $1 \%$. 


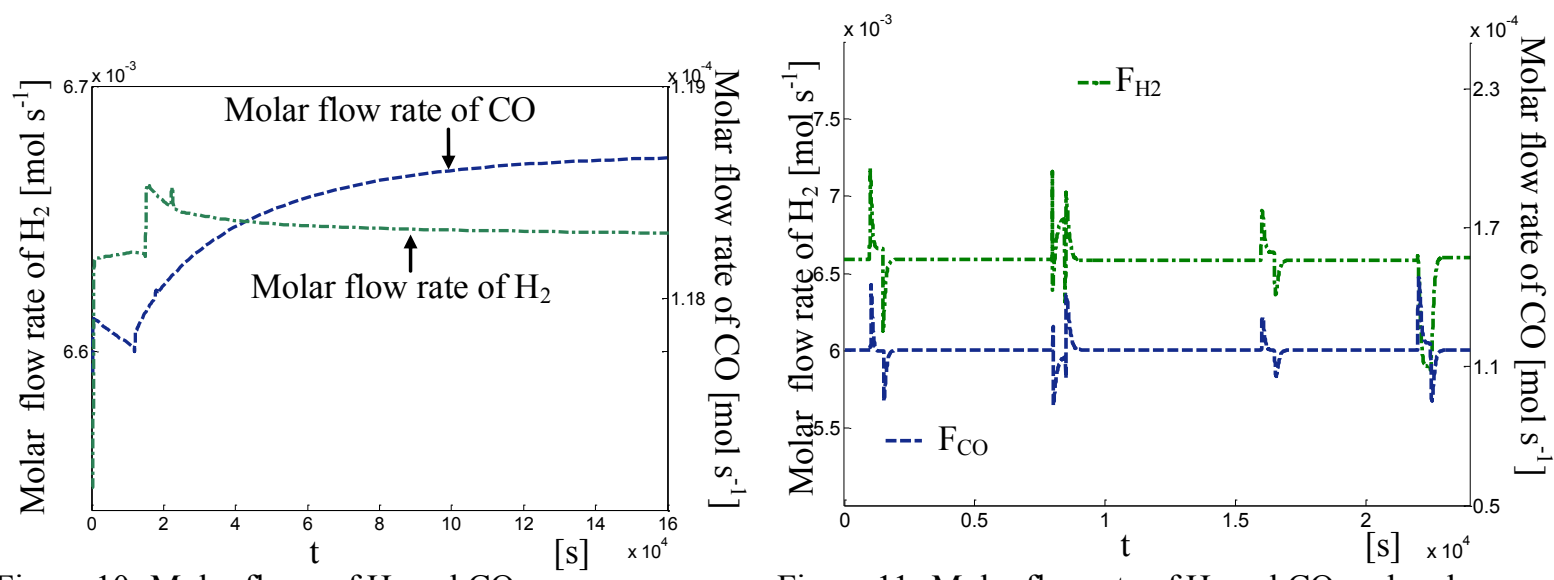

Figure 10- Molar flows of $\mathrm{H}_{2}$ and $\mathrm{CO}$ for $1 \%$ setpoint changes.

Figure 11- Molar flowrate of $\mathrm{H}_{2}$ and $\mathrm{CO}$ under changes in the non-manipulated inputs.

In Figure 11 we can see the $\mathrm{H}_{2}$ and $\mathrm{CO}$ molar flows under steps in the following input variables: $\mathrm{F}_{\mathrm{C} 2 \mathrm{H} 5 \mathrm{OH}}, \mathrm{F}_{\mathrm{H} 20}$, $\mathrm{T}_{\mathrm{F}, \mathrm{S} 1}, \mathrm{~T}_{\mathrm{F}, \mathrm{S} 2}$. The steps are made using increases of $10 \%$ in the $\mathrm{F}_{\mathrm{C} 2 \mathrm{H} 5 \mathrm{OH}}, \mathrm{F}_{\mathrm{H} 20}$ manipulated variables and a $5 \%$ increase in the temperatures $\left(\mathrm{T}_{\mathrm{F}, \mathrm{S} 1}, \mathrm{~T}_{\mathrm{F}, \mathrm{S} 2}\right)$. We can see a good performance of the controller under perturbations in the non-manipulated inputs and we can say that the controller is robust under perturbations in the nonmanipulated input variables.

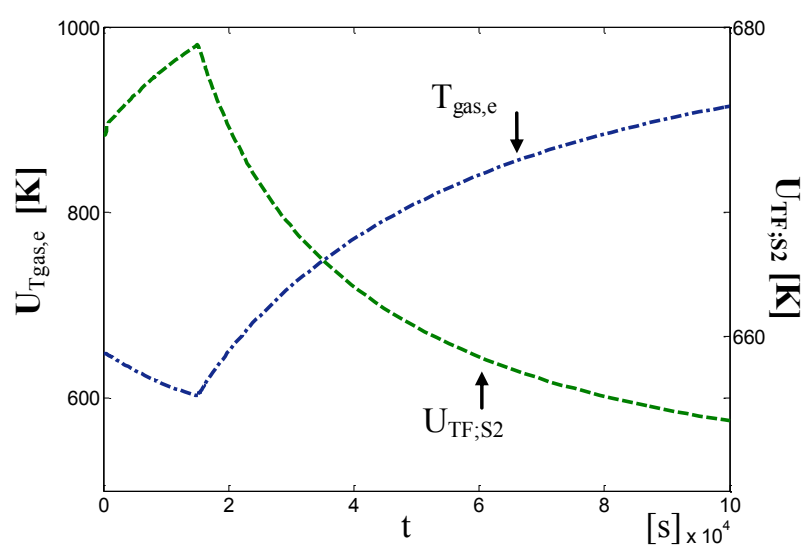

Figure 12- Controller outputs for $1 \%$ set point changes at $\mathrm{t}=400$ and $\mathrm{t}=15000 \mathrm{~s}$.

In figure 12 we can see the controller outputs that correspond to the simulation of Figure 10.

\section{Structure 5}

In figure 13 we can see the molar flows of $\mathrm{H}_{2}$ and $\mathrm{CO}$ for the Structure 5 under the following variation: $1 \%$ increase in the $\mathrm{CO}$ reference and $1 \%$ in the reference of $\mathrm{H}_{2}$ at $=500 \mathrm{~s}$ and $\mathrm{t}=12000 \mathrm{~s}$, respectively. In this case the response time is also extremily large what would make Structure 5, as Structure 4, non viable. 


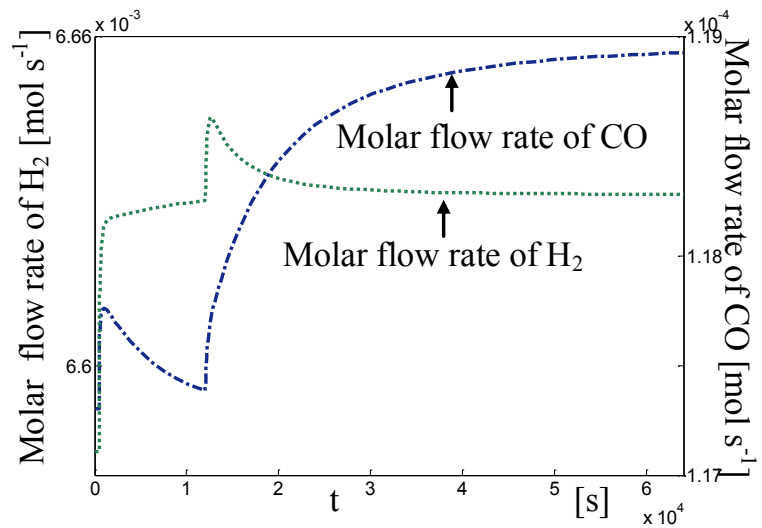

Figure 13- Molar flows of $\mathrm{H}_{2}$ and $\mathrm{CO}$ for $1 \%$ setpoint changes.

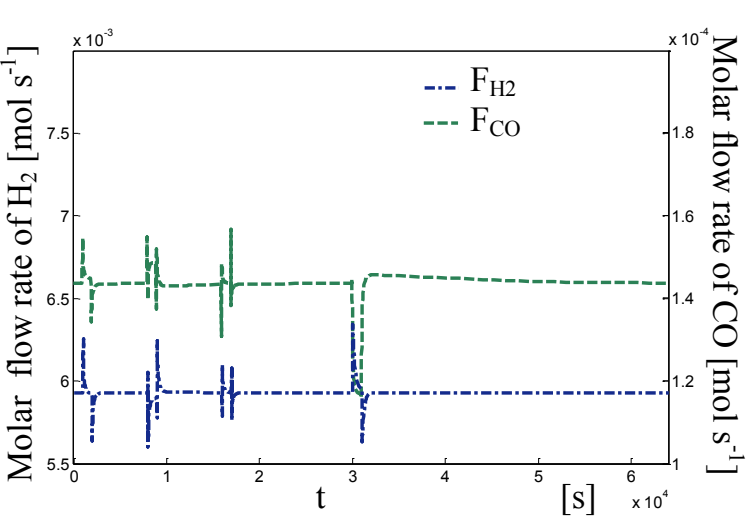

Figure 14- Molar flows of $\mathrm{H}_{2}$ and $\mathrm{CO}$ under changes in the MV.

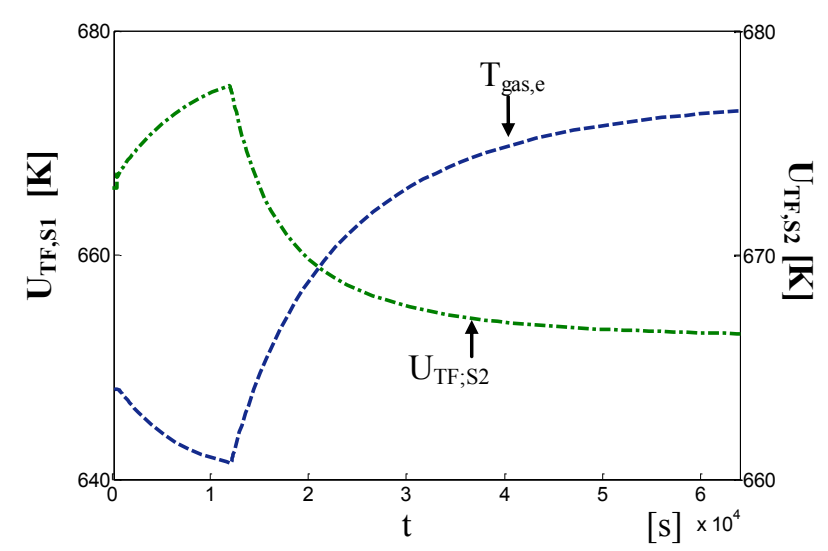

Figure 15 - Controller outputs for $1 \%$ set point changes at $t=500$ and $t=12000 s$.

In Figure 14 we can see the $\mathrm{H}_{2}$ and $\mathrm{CO}$ molar flows under step changes in the following input variables: $\mathrm{F}_{\mathrm{C} 2 \mathrm{H} 5 \mathrm{OH}}$, $\mathrm{T}_{\mathrm{H} 2 \mathrm{O}}, \mathrm{T}_{\mathrm{F}, \mathrm{S} 1}, \mathrm{~T}_{\mathrm{F}, \mathrm{S} 3}$. The controller has a good performance under these perturbations in the input variables. In this case we have also evaluated the controller outputs, as is shown in Figure 15.

\section{Change of operating conditions test}

Since structure 1 has de best performance another robustness test is done for this structure. It consists on the change of the operating conditions. The simulations performed are $10 \%$ setpoint changes in both controlled variables (the same scenario of Figures 2 and 3) but from different operating points. The operation points are:

- $\mathrm{OP}_{1}\left(\Delta \mathrm{F}_{\mathrm{C} 2 \mathrm{H} 5 \mathrm{OH}}\right): 10 \%$ ethanol input increase while keeping the other 5 remain constant

- $\mathrm{OP}_{2}\left(\Delta \mathrm{F}_{\mathrm{H} 2 \mathrm{O}}\right): 10 \%$ water input increase while keeping the other 5 remain constant

- $\mathrm{OP}_{3}\left(\Delta \mathrm{T}_{\text {gas,e }}\right): 10 \%$ furnace temperature input increase in the gas entrance while keeping the other 5 remain constant

- $\mathrm{OP}_{4}\left(\Delta \mathrm{T}_{\mathrm{F}, \mathrm{S} 2}\right): 10 \%$ furnace temperature input increase in the stage 2 while keeping the other 5 remain constant

From the simulations realised to evaluate the performance of the controller under different operating conditions, we conclude that the performance of the controller is similar regarding all points of operation that we tested, proving the robustness of the controller. However, some operating points are more favorable for the performance of the controller, such as $\mathrm{O}_{\mathrm{P} 2}$, which has a lower overshoot to changes in the references. All this can be seen in Figures 16 and 17 where we see the controlled variables facing setpoint changes in both loops. 


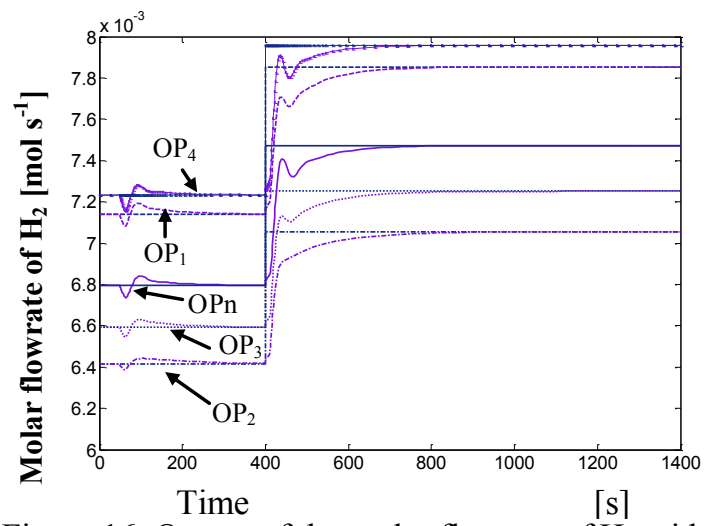

Figure 16: Output of the molar flowrate of $\mathrm{H}_{2}$ with $10 \%$ setpoint changes at $\mathrm{t}=50 \mathrm{~s}$ and $\mathrm{t}=400 \mathrm{~s}$.

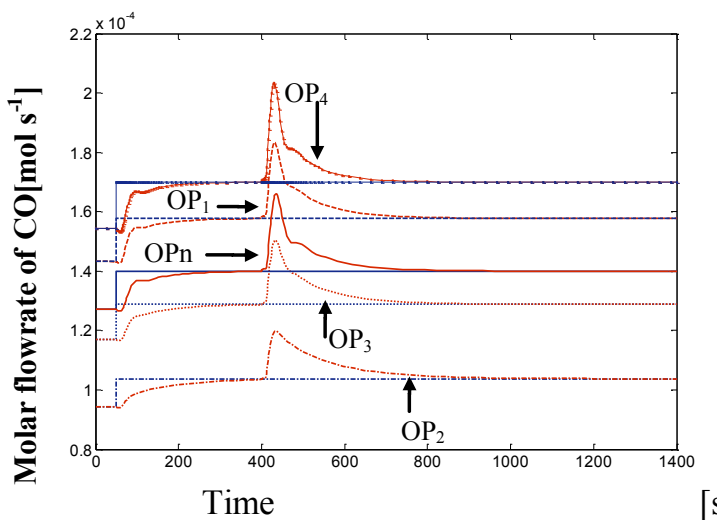

Figure 17: Output of the molar flowrate of $\mathrm{CO}$ with $10 \%$ setpoint changes at $\mathrm{t}=50 \mathrm{~s}$ and $\mathrm{t}=400 \mathrm{~s}$.

\section{Analysis of results}

The great non-linearity of the system and the interaction between loops has made impossible to give the same treatment for the analysis of the different structures. Because of that, the tuning methods are not the same and the simulation scenarios are not the same for each one of the analysed structures. But some general caracteristics of the different structures can be obtained.

When we study the behaviour of different structures we can conclude that the time response is different: when we use Structure 1, where both manipulated variables are flows, the response is a lot faster than in the other cases. For example, in Structure 2 the controlled outputs spend more than 2000s to reach their final value while in Structure 1, the controlled outputfs spend 200s to reach the final value. With respect to the response time, the worst structure is Structure 4 where the time required to reach stationary conditions is at least an order of magnitude higher than for the other structures. Structures 3 has the faster response of structures 2, 3 and 5, and Structure 5 has the slower one. This conclusion is very significant in the implementation of the controller, indicating the superiority of Structure 1 according to the criterion of time response.

In all simulations, the manipulated and controlled variables don't have oscillations. Therefore, we cannot say that a structure will be better or worse than the other evaluating this criterion.

In the simulation tests, the different control structures are subjected to different changes in the references because some structures did not accept larger setpoint changes. Specifically, Structures 1 and 2 are the only ones that support changes of $10 \%$ in both setpoints with appropriate dynamics. On the otherhand, the rest of the control structures are subjected to changes of $5 \%, 2 \%$ and $1 \%$ because larger setpoint changes were not possible to control.

When analysing the behaviour of the controlled system under changes in inputs that are not used as control variables, we did not see important differences between structures. We can generally conclude that all structures showed a good rejection of non-manipulated inputs disturbances.

Finally, for Structure 1, the behaviour of the controller in different operating conditions has been studied. The simulations have shown that there are not important performance changes what indicates that the control system is robust to changes in the operating conditions.

\section{Conclusions}

After several simulation tests applied to five different control structures for the control of the ethanol steam reformer, it can be concluded that it is possible to control the reformer with a decentralised $2 \mathrm{X} 2$ control with PI in both loops. With such a control system, $10 \%$ setpoint changes in the hydrogen and CO exit flowrates can be tracked, disturbances introduced by the non-manipulated inputs can be rejected and the operating conditions can be changed (10\%). The best control structure (pair of inputs that control the hydrogen and CO exit flowrates) is Structure 1, which consists in the manipulation of the ethanol input flowrate and the water input flowrate. 


\section{Nomenclature}

$\begin{array}{ll}\mathrm{t} & \text { time }(\min ) \\ \mathrm{T} & \text { temperature }(\mathrm{K}) \\ \mathrm{T}_{\mathrm{F}} & \text { furnace temperature }(\mathrm{K}) \\ \mathrm{OP}_{\mathrm{n}} & \text { operating point }\end{array}$

Subscripts

e reactor input

out reactor output

gas gas

$\mathrm{C} 2 \mathrm{H} 5 \mathrm{OH}$ relative to ethanol

$\mathrm{H} 2 \mathrm{O}$ relative to water

$\mathrm{C} 2 \mathrm{H} 4 \mathrm{O}$ relative to acetaldehyde

$\mathrm{H} 2$ relative to hydrogen

$\mathrm{CO}$ relative to carbon monoxide

$\mathrm{O} 2$ relative to oxygen

S1 stage 1

S2 stage 2

S3 stage 3

Greek letters

$\Delta$ increment

\section{Acknowledgement}

This work has been funded through MICINN projects DPI2011- 25649 and CTQ2009-12520.

\section{References}

[1] V. García, E. López, M. Serra and J. Llorca, Dynamic modeling of a three-stage low-temperature ethanol reformer for fuel cell application, J. Power Sources 192, 2009, 208-215.

[2] V. García, M. Serra and J. Llorca. Controllability study of an ethanol steam reforming process for hydrogen production. Journal of Power Sources, 196, 2011, 4411-4417.

[3] J. Pukrushpan, A.Stefanopoulou, S. Varigonda, L.M. Pedersen, S. Ghosh, H. Pen, Control of Natural Gas Catalytic Partial Oxidation for Hydrogen Generation in Fuel Cell Applications“", IEEE Transaction on Control System Technology, 13, 2005, 3-14.

[4] M. Baldea and P. Daoutidis, Dynamics and control of autothermal reactors for the production of hydrogen, Chem. Eng. Sci. 62, 2007, 3218-3230. 